\title{
Analisis Miskonsepsi Siswa SD pada Materi Gaya dan Gerak
}

\author{
Rizki Halimah Nasution', Tommy Tanu Wijaya ${ }^{2}$, M. Jaya Adi Putra ${ }^{3}$, Neni Hermita ${ }^{4 *}$ \\ 1,3,4 Program Studi Pendidikan Guru Sekolah Dasar, Universitas Riau \\ 2, Department mathematics and statistics, Guangxi Normal University \\ *Correspondence Address: neni.hermita@lecturer.unri.ac.id
}

\begin{abstract}
This research is to find out and describe elementary students misconception on the concept of force and motion. Data collection methods using tests in the form of four tier tests and interviews. Sampling techniques through saturated sampling is applied to obtain students who will be examined throughbout the fifth grade of SDN 147 Pekanbaru. The research data were analyzed using descriptive quantitative analysis. The results showed that elementary students misconceptions could be categorized as "medium" with an average of 54,29\% or totaling 76 students from 140 students studied. The bighest misconception on the concept spring force with a misconception of $75 \%$ or a total of 105 students from 140 students studied. The lowest misconception on the concept of the influence of force on the motion of objects with a misconception of 19,29\% or a total of 27 students from 140 students studied. Comparison of the percentage of misconceptions of male and female students on the concepts of force and motion included in "medium category", with an average percentage of misconceptions that occur in male students by $51,56 \%$ and female students by $51,31 \%$. The factors causing the occurrence of misconceptions in students come from students, the context and teaching methods.
\end{abstract}

Keywords: misconceptions, the force and motion, elementary students

\begin{abstract}
ABSTRAK
Penelitian ini bertujuan untuk mengetahui dan mendeskripsikan miskonsepsi siswa sekolah dasar pada materi gaya dan gerak. Metode pegumpulan data menggunakan tes berupa four tiet test dan wawancara. Teknik pengambilan sampel melalui sampling jenuh yaitu seluruh siswa kelas V SDN 147 Pekanbaru. Data hasil penelitian dianalisis menggunakan analisis kuantitatif deskriptif. Hasil penelitian menunjukkan bahwa miskonsepsi yang terjadi pada siswa sekolah dasar termasuk dalam kategori miskonsepsi "sedang" dengan rata-rata 54,29\% atau berjumlah 76 siswa dari 140 siswa. Miskonsepsi tertinggi pada sub indikator terkait gaya pegas dengan miskonsepsi sebesar $75 \%$ atau berjumlah 105 siswa dari 140 siswa. Miskonsepsi terendah pada sub indikator pengaruh gaya pada gerak benda dengan persentase miskonsepsi sebesar 19,29\% atau berjumlah 27 siswa dari 140 siswa. Perbandingan persentase miskonsepsi siswa laki-laki dan perempuan pada materi gaya dan gerak termasuk dalam kategori "sedang" dengan rata-rata miskonsepsi yang terjadi pada siswa lakilaki sebesar 51,56\% dan perempuan sebesar 51,31\%. Faktor penyebab terjadinya miskonsepsi pada siswa berasal dari peserta didik, konteks dan metode mengajar.
\end{abstract}

Kata kunci: miskonsepsi, gaya dan gerak, siswa sekolah dasar

\section{PENDAHULUAN}

Tujuan pendidikan secara umum adalah mengarahkan siswa untuk bisa mandiri dalam menjalani hidupnya. Siswa mampu memahami konsep-konsep ilmiah dan mampu mengaplikasikan ilmunya dalam kehidupannya menjadi salah satu tujuan pembelajaran IPA. Siswa SD bisa memahami konsep, bisa mengembangkan keterampilan ilmiahnya, dan bisa bersikap sesuai nilai-nilai yang 
didapatkan dalam pembelajarannya menjadi tujuan pembelajaran IPA di sekolah dasar. Fenomena alam menjadi dasar dari pembelajaran IPA, akan lebih bagus jika pembelajaran IPA disekolah bisa menjadi wahana bagi siswa untuk belajar mengenai diri siswa dan lingkungan siswa (llhami et al., 2019). Lingkungan sekitar siswa dapat dimanfaatkan sebagai sumber belajar (Meiningsih, 2019).

Upaya dalam memahami sebuah konsep siswa diharapkan bisa menghubungkan semua konsep yang dipelajari dengan baik dan benar, termasuk konsep-konsep yang abstrak. Guru seharusnya tahu tentang masalah belajar siswa agar dapat dilakukan cara yang tepat untuk mengatasi masalah siswa (Handayani, 2018). Salah satu masalah yang sering ditemukan adalah miskonsepsi. Miskonsepsi adalah suatu konsep yang tidak sesuai dengan konsep yang diakui para ahli (Suparno, 2013).

Menemukan Miskonsepsi dan mengetahuinya terjadi pada siswa akan membantu guru dalam mengatasi dan memperbaiki miskonsepsi yang dialami siswanya. Miskonsepsi lebih sering terjadi tanpa disadari oleh siswa yang mengalaminya sehingga menghambat proses pembelajaran berikutnya (Didik, 2020). Miskonsepsi bersifat resisten terhadap masuknya ide-ide atau gagasangagasan baru yang lebih ilmiah, bahkan peserta didik yang mengalami miskonsepsi dapat menolak ide-ide atau gagasan-gagasan baru yang diterimanya, sehingga mereka sulit untuk menerima konsepsi baru yang ilmiah yang pada akhirnya menghambat pada tercapainya pemahaman materi ajar yang utuh (Hermita et al., 2018). Penyebab miskonsepsi secara garis besar ada lima kelompok, yaitu: siswa, guru, buku teks, konteks, dan metode mengajar (Suparno, 2013).

Berdasarkan penelitian sebelumnya tentang miskonsepsi yang dilakukan di tingkat perguruan tinggi oleh Neni Hermita (2017) bahwa miskonsepsi yang dialami oleh calon guru sekolah dasar PGSD FKIP Universitas Riau ditemukan beberapa jenis miskonsepsi yang terjadi pada sebagian besar mahasiswa terkait materi listrik statis, yaitu: (1) benda bermuatan listrik tidak dapat menarik benda netral; (2) benda netral adalah benda yang tidak mengandung muatan listrik; dan (3) besar gaya tarik menarik antara dua benda bermuatan bergantung pada besar muatan benda (Hermita, 2017). Berdasarkan penelitian tentang miskonsepsi gaya dan gerak yang dilakukan oleh Apriliana Helinda (2015) bahwa miskonsepsi yang dialami siswa kelas IV SDN Jember Lor 02 Tahun pelajaran 2014/2015 dengan persentase miskonsepsi yang berbeda pada setiap butir soalnya pada 32 orang siswa, persentase tertinggi pada konsep gerak jatuh benda sebesar 78,13\% (25 siswa), dan persentase terendah yaitu 15,63\%. Terdapat pada konsep pengaruh gaya terhadap kecepatan gerak benda (Helinda, 2015). Miskonsepsi bisa saja terjadi pada siswa SD sampai kepada mahasiswa diketahui dari penelitian yang sudah dilakukan sebelumnya.

Penelitian sebelumnya tentang materi IPA Fisika terkait gaya dan gerak di SD dilakukan oleh (Helinda, 2015; Khoiriyah, 2018; Rahmi, 2013), namun dengan format instrument yang berbeda, tempat, waktu, sampel dan variabel penelitian yang berbeda, penelitian sebelumnya menggunakan format two tier test dan three tier test, sedangkan peneliti memakai four tier test, juga terdapat perbedaan sub indikator materi yang dibahas peneliti dengan penelitian sebelumnya.

Tes diagnostik digunakan untuk mendiagnosis miskonsepsi yang dialami siswa sebagai salah satu cara untuk mengatasi miskonsepsi yang terjadi (Wilantika, 2018). Pengembangan tes diagnostik terus diupayakan oleh para peneliti untuk menganalisis miskonsepsi lebih mendalam. Tes diagnostik bisa berupa pilihan ganda dan uraian.

Tes diagnostik yang baik dapat memberikan gambaran akurat mengenai miskonsepsi yang dialami siswa berdasarkan kesalahan yang siswa buat, dan pertanyaan diagnostik yang baik tidak hanya menunjukkan bahwa siswa tidak memahami materi tertentu, tetapi menunjukkan bagaimana siswa berfikir dalam menjawab pertanyaan yang diberikan meskipun jawaban mereka salah (Fariyani, 2015). Salah satu tes dignostik yang bisa digunakan untuk mengetahui kesalahan dalam memahami konsep pada siswa adalah dengan menggunakan test diagnostik four tier test. Tes pilihan ganda empat tingkat (four tier test) dirancang untuk menentukan seberapa kuat siswa menguasai 
konsep melalui tingkat keyakinan dalam menjawab pertanyaan. Instrumen gaya dan gerak four tier test akan digunakan dalam penelitian ini untuk mengetahui miskonsepsi yang dialami oleh siswa.

Tes pilihan ganda empat tingkat adalah tes dignostik multi tier, tingkat pertama adalah pertanyaan pilihan ganda biasa dengan pengacau yang membahas kesalahpahaman tertentu, tingkat kedua yaitu tingkat meminta kepercayaan terhadap jawaban pada pilihan ganda, tingkat ketiga adalah meminta alasan jawaban terhadap pilihan jawaban pilihan ganda, dan tingkat keempat adalah meminta kepercayaan terhadap alasan jawaban pada alasan yang diberikan di tingkat ketiga yaitu berupa penalaran (Gurel et al., 2015). Four tier multiple choice atau yang disebut dengan four tier test dapat mengatasi kesulitan dalam mengidentifikasi konsepsi siswa (Hermita et al., 2017). Hal mendasar untuk mendeteksi miskonsepsi siswa adalah dengan mengembangkan instrumen four ier test, juga diperlukannya ide untuk bisa melihat miskonsepsi yang terjadi (Nurfiyani, 2020). Tes diagnostik empat tingkat dan tes wawancara digunakan untuk mencapai tujuan penelitian, yaitu untuk mengetahui dan mendeskripsikan miskonsepsi siswa sekolah dasar pada materi gaya dan gerak.

Sesuai dengan uraian, maka peneliti melaksanakan penelitian tentang analisis miskonsepsi materi gaya dan gerak pada siswa kelas V SDN 147 Pekanbaru dengan menggunakan instrumen Four Tier Test sesuai dengan materi yang ingin diteliti.

\section{METODOLOGI}

Penelitian ini telah dilakukan pada bulan Maret 2020 di SDN 147 Pekanbaru. Penelitian yang dilakukan adalah penelitian deskriptif kuantitatif. Pengumpulan data dilakukan dengan menggunakan tes diagnostik pada siswa kelas V SDN 147 Pekanbaru untuk mengetahui miskonsepsi yang terjadi pada siswa dan juga wawancara dilakukan untuk mendapatkaan informasi mengenai penyebab terjadinya miskonsepsi siswa. Sampel dalam penelitian ditentukan menggunakan teknik sampling jenuh. Teknik sampling jenuh adalah teknik penentuan sampel apabila semua anggota populasi digunakan sebagai sampel (Sugiyono, 2017).

Responden yang menjadi sampel adalah seluruh siswa kelas V SDN 147 Pekanbaru yang terdiri dari 4 kelas dan seluruh responden berjumah 140 siswa. Instrumen yang digunakan terdiri dari soal-soal yang berhubungan dengan materi gaya dan gerak melalui tes 4 tingkat (four tier test). Data penelitian yang diperoleh dari soal tes diagnostik yang sudah dijawab responden akan dianalisis. Lalu hasil dari penelitian diketahui persentase miskonsepsi yang terjadi pada siswa terkait materi gaya dan gerak.

Instrumen four tier test digunakan untuk mengukur tingkat miskonsepsi siswa sekolah dasar. peneliti mengaplikasikan instrumen tes dengan 4 tingkat kesulitan. Miskonsepsi siswa kelas V SD pada materi gaya dan gerak akan diketahui melalui penggunaan instrumen ini. Pengukuran tes dalam penelitian ini menggunakan four tier test (pengukuran empat tingkat). Miskonsepsi dapat diketahui dengan item tes diagnostik yang telah disusun. Item tes divalidasi pada ahli sebelum digunakan, item tes yang valid terdiri dari 15 item diberikan kepada responden yang berjumlah 140 siswa. Selanjutnya hasil jawaban siswa disesuaikan dengan keputusan dalam four tier tes (Hermita, 2017). Panduan penilaian 15 item tes diagnostik four tier test yang sudah diisi responden dapat dilihat pada Tabel 1.

Tabel 1. Keputusan dalam Four Tier- Test

\begin{tabular}{lllll}
\hline $\begin{array}{l}\text { Tingkat } \\
\text { pertama }\end{array}$ & Tingkat kedua & $\begin{array}{l}\text { Tingkat } \\
\text { ketiga }\end{array}$ & $\begin{array}{l}\text { Tingkat } \\
\text { keempat }\end{array}$ & Kategori \\
\hline Benar & Yakin & Benar & Yakin & Paham konsep \\
\hline Benar & Yakin & Benar & Tidak yakin & $\begin{array}{l}\text { Tidak paham } \\
\text { konsep }\end{array}$ \\
\hline Benar & Yakin & Salah & Tidak yakin & Ron \\
\hline
\end{tabular}




\begin{tabular}{llll}
\hline $\begin{array}{l}\text { Tingkat } \\
\text { pertama }\end{array}$ & Tingkat kedua & $\begin{array}{l}\text { Tingkat } \\
\text { ketiga }\end{array}$ & $\begin{array}{l}\text { Tingkat } \\
\text { keempat }\end{array}$ \\
\hline Benar & Tidak Yakin & Benar & Yakin \\
\hline Benar & Tidak Yakin & Benar & Tidak Yakin \\
\hline Benar & Tidak Yakin & Salah & Tidak Yakin \\
\hline Salah & Yakin & Benar & Tidak Yakin \\
\hline Salah & Yakin & Salah & Tidak Yakin \\
\hline Salah & Tidak Yakin & Benar & Tidak Yakin \\
\hline Salah & Tidak Yakin & Salah & Tidak Yakin \\
\hline Benar & Yakin & Salah & Yakin \\
\hline Benar & Tidak Yakin & Salah & Yakin \\
\hline Salah & Yakin & Salah & Yakin \\
\hline Salah & Tidak Yakin & Salah & Yakin \\
\hline Salah & Yakin & Benar & Yakin \\
\hline Salah & Tidak Yakin & Benar & Yakin \\
\hline
\end{tabular}

Sumber: (Hermita, 2017)

Selanjutnya setelah diketahui item miskonsepsi tertinggi, sedang dan terendah maka dilakukanlah wawancara untuk mengetahui penyebab miskonsepsi yang dialami siswa. Setelah dilakukan tes diagnostik pada responden, maka hasil dari tes penelitian diolah dengan menggunakan rumus yang dikemukakan oleh Sudijono (Alawiyah, 2017) yaitu:

$$
P=\frac{F}{N} \times 100 \%
$$

keterangan:

F: frekuensi jawaban siswa tiap butir soal

$\mathrm{N}$ : jumlah siswa

$P$ : persentase jawaban siswa tiap butir soal

100\%: bilangan konstanta

Perhitungan nilai persentase selanjutnya akan digambarkan dalam bentuk tabel/diagram. Selanjutnya menganalisis pada butir soal dan subbab apa siswa mengalami miskonsepsi serta mengelompokkan tingkat miskonsepsi siswa sesuai dengan besar persentasenya pada Tabel 2 yang dikemukakan oleh Suwarna (2013) mengkategorikan tingkat miskonsepsi (Wilantika, 2018) sebagai berikut:

Tabel 2. Kategori Persentase Tingkat Miskonsepsi

\begin{tabular}{ll}
\hline Persentase & Kategori \\
\hline $0-30 \%$ & Rendah \\
$31-60 \%$ & Sedang \\
$61-100 \%$ & Tinggi \\
\hline
\end{tabular}

\section{TEMUAN DAN PEMBAHASAN}

Setelah dilaksanakannya tes konsepsi siswa berupa tes diagnostik four tier test, maka dari hasil jawaban siswa dikelompokkan kedalam empat kategori, yaitu paham konsep (PK), tidak paham konsep (TPK), miskonsepsi (M) dan error (E). Hasil analisis akhir instrument tes diagnostik empat tingkat yang terdiri dari 15 soal pada Tabel 3. 
Tabel 3. Tingkat Pemahaman Siswa pada Materi Gaya dan Gerak

\begin{tabular}{lll}
\hline & Persentase & Jumlah siswa \\
\hline Paham Konsep & $27,14 \%$ & 38 \\
\hline Tidak Paham Konsep & $12,86 \%$ & 18 \\
\hline Miskonsepsi & $54,29 \%$ & 76 \\
\hline Error & $5,71 \%$ & 8 \\
\hline Total & $100 \%$ & 140 \\
\hline
\end{tabular}

Pada Tabel 3 kita bisa mengetahui persentase siswa yang paham konsep sebesar 27,14\% atau berjumlah 38 siswa yang paham konsep dari 140 siswa yang diteliti, dan termasuk dalam kategori "rendah". Persentase tidak paham konsep sebesar 12,86\% atau sebanyak 18 siswa tidak paham konsep juga termasuk dalam kategori "rendah". Persentase miskonsepsi sebesar 54,29\% atau sebanyak 76 siswa mengalami miskonsepsi termasuk kategori "sedang". Persentase error sebesar 27,14\% atau berjumlah 38 siswa dan termasuk kategori "rendah". Persentase miskonsepsi sub indikator materi gaya gerak yang dialami siswa SDN 147 Pekanbaru Semester II dapat dilihat dari Gambar 1.

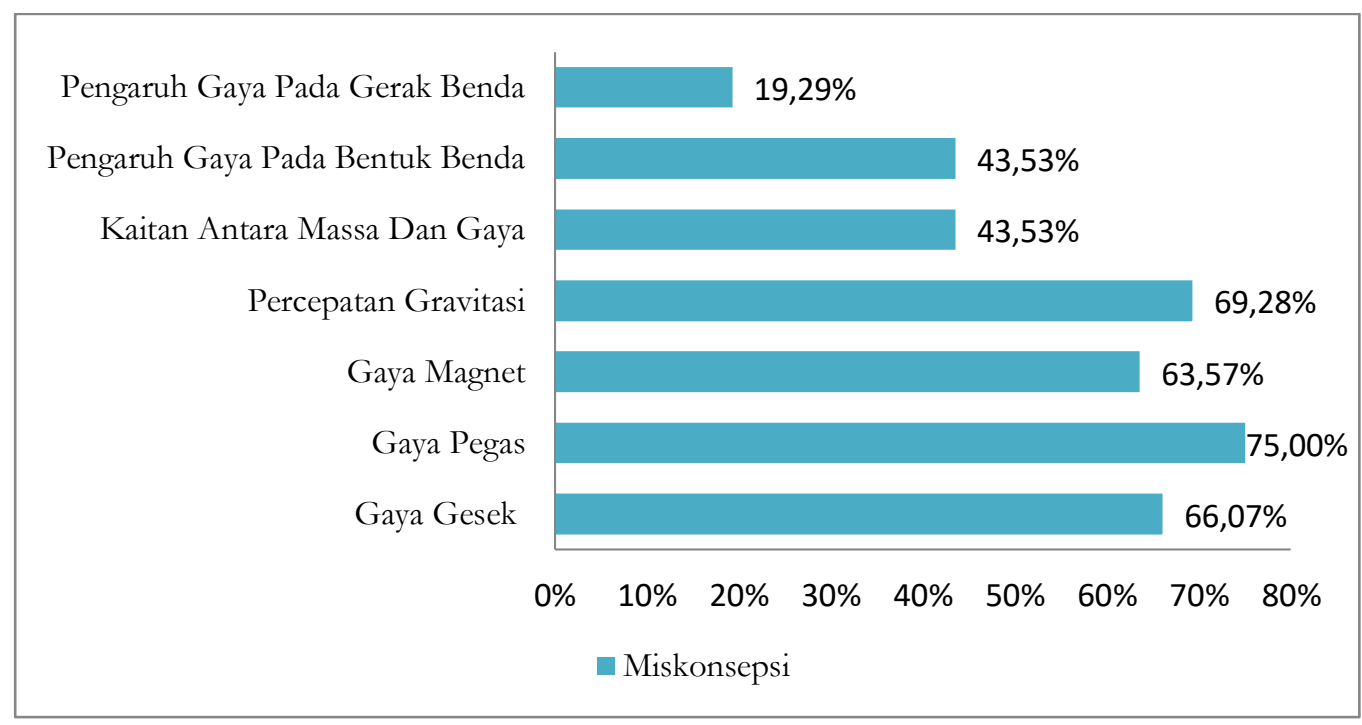

Gambar 1. Persentase Miskonsepsi Siswa SD pada Tiap Sub Indikator

Berdasarkan grafik pada Gambar 1 diketahui miskonsepsi yang dialami siswa termasuk kategori "sedang" dengan rata-rata persentase miskonsepsi siswa sebesar 54,29\% atau berjumlah 76 siswa dari 140 siswa yang diteliti mengalami miskonsepsi. Sub indikator 1 (pengaruh gaya pada gerak benda) dengan persentase miskonsepsi sebesar 19,29\% atau sebanyak 27 siswa dari 140 siswa yang diteliti mengalami miskonsepsi dan termasuk dalam kategori miskonsepsi "rendah". Pada sub indikator 2 (pengaruh gaya pada bentuk benda) dengan jumlah persentase miskonsepsi sebesar 43,57\% atau berjumlah 61 siswa dan termasuk dalam kategori miskonsepsi "sedang". Sub indikator 3 (kaitan antara massa dan gaya) dengan persentase miskonsepsi sebesar 43,57\% atau berjumlah 61 siswa dan termasuk dalam kategori miskonsepsi "sedang".

Sub Indikator 4 (percepatan gravitasi) dengan persantase miskonsepsi sebesar 69,28\% atau berjumlah 97 siswa dari 140 siswa yang diteliti dan termasuk dalam kategori miskonsepsi "tinggi". Sub Indikator 5 (gaya magnet) dengan persentase miskonsepsi sebesar 63,57\% atau berjumlah 89 siswa dan termasuk dalam kategori miskonsepsi "tinggi". Sub Indikator 6 (gaya pegas) dengan persentase miskonsepsi sebesar 75\% atau berjumlah 105 siswa dan termasuk dalam kategori miskonsepsi "tinggi". Dan terakhir pada sub indikator 7 (gaya gesek) dengan persentase miskonsepsi sebesar 66,07\% atau berjumlah 92 siswa dan termasuk dalam kategori miskonsepsi 
"tinggi". Dari persentase data yang disajikan tersebut membuktikan bahwa banyak siswa kelas V SDN 147 Pekanbaru semester II yang mengalami miskonsepsi pada materi gaya dan gerak yang telah diujikan. Miskonsepsi tingkat persentase tertinggi yang terjadi pada siswa yaitu pada sub indikator 6 gaya pegas dan miskonsepsi terendah pada sub indikator pengaruh gaya pada gerak benda.

Selanjutnya data hasil tes penelitian yang telah dilakukan maka dapat kita lihat persentase miskonsepsi pada tiap butir soal pada Tabel 4 .

Tabel 4. Persentase Miskonsepsi Siswa pada Tiap Butir Soal

\begin{tabular}{ccl}
\hline \multirow{2}{*}{ No Soal } & \multicolumn{2}{c}{ Miskonsepsi } \\
\cline { 2 - 3 } & Jumlah Siswa & Persentase \\
\hline 1 & 32 & $22.86 \%$ \\
\hline 2 & 72 & $51,43 \%$ \\
\hline 3 & 121 & $86,43 \%$ \\
\hline 4 & 71 & $50,71 \%$ \\
\hline 5 & 89 & $63,57 \%$ \\
\hline 6 & 51 & $36,42 \%$ \\
\hline 7 & 22 & $15,71 \%$ \\
\hline 8 & 88 & $62,86 \%$ \\
\hline 9 & 33 & $23,57 \%$ \\
\hline 10 & 84 & $60 \%$ \\
\hline 11 & 87 & $62,14 \%$ \\
\hline 12 & 112 & $80 \%$ \\
\hline 13 & 89 & $63,57 \%$ \\
\hline 14 & 97 & $69,29 \%$ \\
\hline 15 & 105 & $75 \%$ \\
\hline
\end{tabular}

Berdasarkan Tabel 4, dapat diketahui persentase miskonsepsi siswa tertinggi yaitu pada soal nomor 3 sebesar $86,43 \%$ atau berjumlah 121 siswa yang mengalami miskonsepsi pada butir soal ini dari 140 siswa yang diteliti. Sedangkan persentase miskonsepsi terendah yaitu pada soal nomor 7 sebesar $15,71 \%$ atau berjumlah 22 siswa yang miskonsepsi pada butir soal ini dari 140 siswa yang diteliti. Kemudian tingkat miskonsepsi yang terjadi pada siswa pada tiap butir soalnya akan dikelompokkan kedalam tiga kategori, yaitu kategori tingkat miskonsepsi rendah, sedang, dan tinggi. Tingkat miskonsepsi yang dialami siswa dengan kategori rendah terdapat pada tiga soal yaitu pada soal nomor 1, 7 dan 9 dengan persentase miskonsepsi pada soal nomor 1 sebesar 22,85\%, persentase soal nomor 7 sebesar $15,71 \%$ dan pada soal nomor 9 sebesar $23,57 \%$.

Tingkat miskonsepsi yang dialami siswa dengan kategori sedang terdapat pada tiga soal yaitu pada soal nomor 2, 4 dan 6 dengan persentase miskonsepsi pada soal nomor 2 sebesar $51,43 \%$, persentase soal nomor 4 sebesar 50,71\% dan pada soal nomor 6 sebesar $36,42 \%$. Selanjutnya tingkat miskonsepsi yang dialami siswa dengan kategori tinggi terdapat pada sembilan soal yaitu pada soal nomor $3,5,8,10,11,12,13,14,15$ dengan persentase miskonsepsi pada soal nomor 3 sebesar $86,43 \%$, soal nomor 5 sebesar $63,57 \%$, soal nomor 8 sebesar $62,86 \%$, persentase soal nomor 10 sebesar $60 \%$ dan pada soal nomor 11 sebesar $62,14 \%$., persentase soal nomor 12 sebesar 80\%, pada soal nomor 13 sebesar 63,57, pada soal nomor 14 sebesar 69,29\% dan persentase soal nomor 15 sebesar 75\%. Berdasarkan banyaknya jumlah butir soal yang termasuk dalam tingkat miskonsepsi kategori tinggi dapat kita ketahui bahwa banyak siswa kelas V SDN 147 Pekanbaru yang mengalami miskonsepsi pada materi gaya dan gerak ini.

Selanjutnya perbandingan miskonsepsi berdasarkan gender (siswa laki-laki dan siswa perempuan) dimana kita bisa melihat siswa manakah yang lebih banyak mengalami miskonsepsi pada materi gaya dan gerak dan berapakah persentase miskonsepsi yang dialami oleh siswa yang ditampilkan grafik pada Gambar 2. 


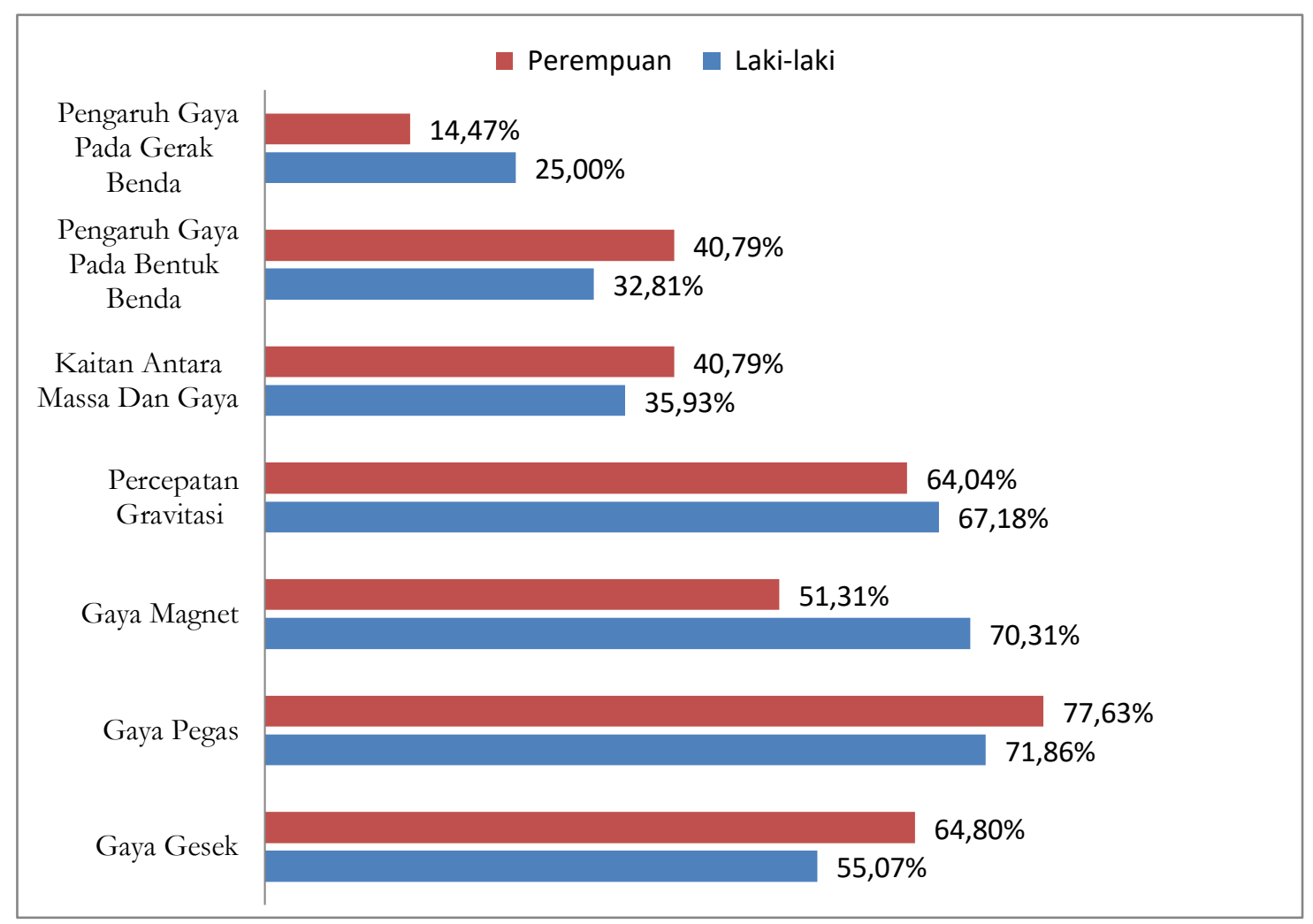

Gambar 2. Persentase Perbandingan Miskonsepsi per Gender

Berdasarkan grafik pada Gambar 2. diketahui perbandingan persentase miskonsepsi siswa laki-laki dan perempuan pada materi gaya dan gerak, jika dirata-ratakan miskonsepsi laki-laki sebesar 51,56\% dikategorikan miskonsepsi "sedang" dan perempuan sebesar 51,31\% dikategorikan "sedang" juga. Pada sub indikator 1 (pengaruh gaya pada gerak benda) siswa perempuan memiliki persentase miskonsepsi sebesar $14,47 \%$ dan dikategorikan miskonsepsi "rendah" dan laki-laki sebesar 25\% dan dikategorikan miskonsepsi "rendah" juga. Pada sub indikator 2 (pengaruh gaya pada bentuk benda) miskonsepsi siswa perempuan sebesar 40,79\% dan laki-laki sebesar 32,81\% dan pada sub indikator kedua ini baik laki-laki maupun perempuan miskonsepsinya dikategorikan "sedang". Pada sub indikator 3 (kaitan antara massa dan gaya) miskonsepsi siswa perempuan sebesar 40,79\% dan laki-laki sebesar 35,93\% dan keduanya juga dikategorikan miskonsepsi "sedang". Pada sub indikator 4 (percepatan gravitasi) miskonsepsi siswa perempuan sebesar 64,04\% dan laki-laki sebesar 67,18\% dan miskonsepsi keduanya dikategorikan "tinggi".

Pada sub indikator 5 (gaya magnet) miskonsepsi siswa perempuan sebesar 51,31\% dan laki-laki sebesar 70,31\% dan keduanya juga dikategorikan miskonsepsi "tinggi". Pada sub indikator 6 (gaya pegas) miskonsepsi siswa perempuan sebesar 77,63\% dan laki-laki sebesar 71,86\% dan keduanya juga dikategorikan miskonsepsi "tinggi". Pada sub indikator 7 (gaya gesek) siswa perempuan yang mengalami miskonsepsi sebesar 64,80\% dan masuk pada kategori "tinggi", sedangkan pada laki-laki miskonsepsi sebesar 55,07\% dan masuk pada kategori "tinggi” juga.

Miskonsepsi yang dialami siswa laki-laki banyak terjadi pada sub indikator percepatan gravitasi, gaya magnet dan pengaruh gaya pada gerak benda. sedangkan perempuan banyak mengalami miskonsepsi pada sub indikator gaya pegas, gaya gesek, kaitan antara massa dan pengaruh gaya pada bentuk benda. Miskonsepsi tertinggi terjadi pada siswa perempuan pada sub indikator gaya pegas dan miskonsepsi terendah juga terjadi pada siswa perempuan pada sub indikator pengaruh gaya pada gerak benda. 
Diketahui penyebab terjadinya miskonsepsi pada siswa melalui wawancara yang dilakukan oleh peneliti kepada 7 siswa. Berdasarkan hasil wawancara siswa diketahui terjadi miskonsepsi pada konsep gaya pegas disebabkan berasal dari peserta didik sebagaimana dalam cuplikan wawancara berikut ini:

Peneliti: "Tahu gaya pegas?"

Siswa: "Tidak tahu"

Peneliti: "Sudah pernah belajar?"

Siswa: "Pernah, tapi lupa"

Peneliti: "Kenapa lupa?

Siswa : Karena tidak diulang-ulang"

Berdasarkan pernyataan siswa tersebut dapat diketahui penyebab terjadinya miskonsepsi berasal dari peserta didik, materi gaya pegas tidak tertanam kuat pada siswa disebabkan daya ingat siswa yang terbatas. Selanjutnya salah satu penyebab siswa miskonsepsi yaitu prakonsepsi siswa yang didukung oleh lingkungan atau berasal dari konteks sebagaimana dalam cuplikan wawancara berikut ini:

Peneliti: "Saat bermain ketapel, ketika kamu menarik ketapelnya, apa yang terjadi?"

Siswa: "Batunya terlempar jauh"

Peneliti: "Kenapa terlempar jauh?, Karena apa?”

Siswa: "Karena di tarik"

Berdasarkan pernyataan siswa tersebut diketahui penyebab miskonsepsi berasal dari konteks (pengalaman langsung) ketika siswa bermain ketapel. Selanjutnya miskonsepsi bisa berasal dari berbagai faktor, salah satunya berasal ketika proses pembelajaran berlangsung. Berdasarkan cuplikan wawancara berikut ini diketahui bahwa guru mengajar dikelas tanpa media dalam pembelajaran konsep gaya pegas, juga terkait materi gaya gerak belum menggunakan media yang tepat.

Peneliti: "Ketika belajar gaya pegas, ibu gurunya ada membawa media?"

Siswa: "Tidak ada"

Peneliti: "Selain gaya pegas, pada materi gaya dan gerak yang lain belajar pakai media?"

Siswa: "Ada, magnet"

Peneliti: "Ada gak nemu dari buku atau penjelasan dari guru yang membuat kamu bingung dan tidak mengerti?"

Siswa: "Tidak ada"

Berdasarkan pernyataan siswa diketahui penyebab terjadinya miskonsepsi pada siswa berasal dari metode mengajar yang dipakai guru. Berdasarkan pernyataan siswa tersebut diketahui juga bahwa miskonsepsi yang terjadi pada siswa tidak disebabkan guru dan buku teks. Berdasarkan hasil wawancara diketahui faktor penyebab miskonsepsi materi gaya dan gerak yang terjadi pada siswa berasal dari diri siswa sendiri berasal dari konteks, dan juga berasal dari metode mengajar. Tingginya hasil persentase miskonsepsi yang dialami siswa pada materi gaya dan gerak pada penelitian ini serta dilihat dari faktor penyebab siswa mengalami miskonsepsi didukung dan dikuatkan penelitian sebelumnya oleh berdasarkan hasil penelitian yang telah dilakukan oleh (Helinda, 2015; Khoiriyah, 2018; Rahmi, 2013) menguatkan hasil penelitian yang dilakukan peneliti walaupun dengan format instrumen yang berbeda, tempat, waktu, sampel dan variabel penelitian 
yang berbeda namun hasil penelitian yang dilakukan peneliti dapat membuktikan bahwa miskonsepsi masih banyak terjadi pada siswa SD khususnya materi gaya dan gerak ini.

Pada proses pembelajaran, banyak sekali guru yang mengajar memakai metode ceramah tanpa media ketika proses belajar mengajar materi gaya gerak ini, sedangkan siswa beranggapan bahwa guru hanya menjelaskan materi dan siswa hanya mendengarkan dan banyak siswa yang jarang mencatat penjelasan guru. Metode ceramah kurang tepat dalam mengajarkan konsep gaya dan gerak ini, seharusnya guru menggunakan metode mengajar yang bervariasi dan menarik perhatian siswa ketika belajar sehingga siswa termotivasi untuk belajar dan mudah memahami konsep yang di ajarkan oleh guru.

Lingkungan sekitar siswa dapat dimanfaatkan sebagai sumber belajar (Meiningsih, 2019). Ketika siswa bermain, melihat secara langsung gambar ataupun pengalaman siswa ketika belajar dan dalam kehidupan sehari-hari yang berkaitan dengan konsep gaya dan gerak, siswa cenderung lebih percaya konsep sesuai dengan yang di alaminya secara langsung, maka ketika belajar, jika siswa tidak memperhatikan guru dalam menjelaskan, maka siswa akan tetap bertahan pada konsep yang salah sesuai dengan pengalamannya (konteks). Dan metode mengajar yang digunakan guru juga akan berpengaruh pada merubah miskonsepsi siswa yang berasal dari konteks, namun jika metode guru dalam mengajar kurang tepat, maka siswa akan tetap bertahan pada konsep yang di alaminya berdasarkan pengalamannya meskipun konsep tersebut salah.

Siswa yang mengalami miskonsepsi berasal dari diri sendiri bisa disebabkan oleh intuisi yang salah dan keterbatasan daya ingat. Intuisi ini bisa berasal dari pengalaman dan pengetahuan seseorang yang belum jelas kebenarannya. Apabila intuisi siswa salah, jika siswa diberikan pertanyaan atau soal maka siswa akan menjawab tanpa memilki alasan yang jelas dan tidak memiliki bukti atas jawaban yang ia pilih. Kemampuan siswa dalam mengingat tidak sama, ada yang memiliki kemampuan ingatan yang tinggi, kemampuan ingatan sedang dan juga rendah, apabila kemampuan daya ingat siswa rendah maka siswa akan kesulitan dalam menghubungkan konsep yang telah dipelajari dengan konsep yang baru ia terima.

Salah satu cara mengatasi miskonsepsi dengan remediasi. Tetapi, sebelum melakukan remediasi miskonsepsi, penting dilakukan oleh guru mengidentifikasi miskonsepsi siswa terlebih dahulu agar penanganannya bisa tepat dalam meluruskan pemahaman siswa (Yuliati, 2017). Terjadinya miskonsepsi pada siswa tidak terlepas dari konsep yang dimilki oleh gurunya yang mungkin mengalami miskonsepsi (Fadlan, 2016). Mengatasi miskonsepsi agar tidak terus terjadi adalah guru harus memahami dan menguasai materi serta bagaimana guru dalam menyampaikan materi kepada siswa juga rutin memberi evaluasi pembelajaran pada siswa.

\section{SIMPULAN}

Berdasarkan hasil dan pembahasan penelitian, maka dapat disimpulkan bahwa miskonsepsi yang terjadi pada siswa kelas V SDN 147 Pekanbaru pade materi gaya dan gerak cukup tinggi, dari 7 sub indikator yang diteliti, 4 sub indikator dikategorikan tinggi, 2 sub indikator dikategorikan sedang dan 1 sub indikator dikategorikan rendah. Miskonsepsi tertinggi pada konsep gaya pegas dan miskonsepsi terendah pada konsep pengaruh gaya pada gerak benda. Perbandingan persentase miskonsepsi siswa laki-laki dan perempuan pada materi gaya dan gerak jika dirata-ratakan miskonsepsi laki-laki sebesar $51,56 \%$ dikategorikan miskonsepsi sedang dan perempuan sebesar $51,31 \%$ dikategorikan sedang juga. Faktor penyebab miskonsepsi materi gaya dan gerak yang terjadi pada siswa berasal dari diri siswa sendiri, berasal dari konteks, dan juga berasal dari metode mengajar yang dipakai guru. Bagi peneliti selanjutnya yang ingin meneliti miskonsepsi materi gaya dan gerak pada siswa SD penulis merekomendasikan agar peneliti selanjutnya bisa memberikan remediasi pada miskonsepsi yang berhubungan dengan materi gaya dan gerak ini. 


\section{REFERENSI}

Alawiyah, N. S. (2017). Identifikasi Miskonsepsi Siswa dengan Menggunakan Metode Indeks Respon Kepastian (IRK) pada Materi Impuls dan Momentum Linear di SMA Negeri 2 Banda Aceh. Jurnal Ilmiah Mahasiswa (JIM) Pendidikan Fisika, 2(2), 272-276.

Didik, L, A., Wahyudi, M., Kafrawi, M. (2020). Identifikasi Miskonsepsi dan Tingkat Pemahaman Mahasiswa Tadris Fisika pada Materi Listrik-Dinamis Menggunakan 3-Tier Diagnostic Test. JNSI : Journal of Natural Science and Integration, 3(2), 128-137.

Fadlan, A. (2016). Model Pembelajaran Konflik Kognitif untuk Mengatasi Miskonsepsi Pada Mahasiswa Tadris Fisika Kualifikasi S.1 Guru Madrasah. Jurnal Pendidikan MIPA, 1(2).

Fariyani, Q., dkk. (2015). Pengembangan Four Tier Test. Journal of Education Innovative Science, 4(2), $41-49$.

Gurel, D. K., Eryilmaz, A., \& MCDermot, L, C. (2015). A Review and Comparison of Diagnostic Instruments to Identify Students ' Misconceptions in Science. Eurasia Journal Of Mathematics Science And Technology Education, 11(5), 989-1008. https://doi.org/10.12973/eurasia.2015.1369a

Handayani, A., R. (2018). Penggunaan Tes Diagnostik (Three Tier dan Four Tier) Untuk Mengidentifikasi Miskonsepsi Siswa Dalam Pembelajaran Sains. PROCIDING SEMINAR NASIONAL MIPA IV Banda Aceh, www.conference.unsyiah.ac.id/SN-MIPA., 144-148.

Helinda, A. (2015). Analisis Miskonsepsi Tentang Gaya Dan Gerak Pada Siswa Kelas IV SDN Jember Lor 02 Tahun Pelajaran 2014/2015. Jurnal Kependidikan Universitas Jember Digital Repository.

Hermita, N., Suhandi, A., Syaodih, E., \& Samsudin, A. (2017). Level Conceptual Change Mahasiswa Calon Guru SD terkait Konsep Benda Netral Sebagai Efek Implementasi VMMSCCText. WaPFi (Wahana Pendidikan Fisika), 2(2), 71.

Hermita, N., Suhandi, A., Syaodih, E. (2017). Identifikasi Miskonsepsi Pada Materi Listrik Statis Pada Mahasiswa Calon Guru Sekolah Dasar. Joernal Pendidikan, 1, 336-340.

Hermita, N., dkk. (2017). Constructing and Implementing a Four Tier Test about Static Electricity to Diagnose Pre-service Elementary School Teacher ' Misconceptions Constructing and Implementing a Four Tier Test about Static Electricity to Diagnose Preservice Elementary School Teacher. Journal of Physics: Conference Series 895(01)., 1-7.

Hermita, N., Suhandi, A., Syaodih, E., Samsudin, A., \& Mahbubah, K. (2018). Constructing VMMSCCText for Re-conceptualizing Students ' Conception. Journal of Applied Environmental and Biological Sciences, 8(3), 102-110. 
Ilhami, A., Riandi, R., and Sriyati, S. (2019). Implementation of Science Learning With Local Wisdom Approach Toward Environmental Literacy. Journal of Physics: Conference Series, 1157 (2), 0-5. https://doi.org/10.1088/1742-6596/1157/2/022030

Khoiriyah, A. F. (2018). Identifikasi Miskonsepsi Siswa Dengan Menggunakan Metode Certainty Of Respense Index (CRI) Materi Gaya Dan Gerak Kelas IV MI Nurul Huda Di Ponerogo. Central Library Of Maulana Malik. Ibrabim State Islamic University Of Malang.

Meiningsih, D., Alimah, S., \& Anggraito, Y., U. (2019). Majalah IT-FLY VA : Alternatif Pilihan Sumber Belajar Biologi. Jurnal Phenomenon, 09(1), 10-20.

Nurfiyani, Y., Adiputra, M, J., \& Hermita, N. (2020). Analisis Miskonsepsi Siswa SD Kelas V Pada Konsep Sifat-sifat Cahaya. Journal of Natural Science and Integration, 3(1), 77-86.

Rahmi, A. (2013). Identifikasi Miskonsepsi IPA-Fisika Berdasarkan Jenjang Pendidikan (SD, SMP, SMA) menggunakan tes three-tier pada pokok bahasan gerak dan gaya. Institutional Repository UIN Sunan Kali Jaga Yogyakarta, www.digilib.uin-suka.ac.id, 1-131.

Sugiyono. (2017). Metode Penelitian Pendidikan (Pendekatan Kuantitatif, Kualitatif dan R\&D). Bandung: Alfabeta.

Suparno, P. (2013). Miskonsepsi dan Perubahan Konsep Dalam Pendidikan Fisika. Jakarta: Grasindo.

Wilantika, N., Khoiri, N., \& Hidayat, S. (2018). Pengembangan Penyusunan Instrumen Four-Tier Diagnostik Test untuk Mengungkap Miskonsepsi Materi Sistem Ekskresi di SMA Negeri 1 Mayong Jepara. Jurnal Phenomenon, 08(2), 87-101.

Yuliati, Y. (2017). Miskonsepsi Siswa pada Pembelajaran IPA Serta Remediasinya. Jurnal Bio Education, 2(2), 50-58. 